\title{
Denitrifcation in an integrated bioelectro-photocatalytic system
}

Zhi-Qi Lin ${ }^{\dagger}$, Shi-Jie Yuan ${ }^{\dagger}$, Wen-Wei Li, Jie-Jie Chen*, Guo-Ping Sheng, Han-Qing Yu*

CAS Key Laboratory of Urban Pollutant Conversion, Department of Chemistry, University of Science \& Technology of China, Hefei, 230026, China

${ }^{\dagger}$ These authors contributed equally.

*Corresponding authors:

Dr. Jie-Jie Chen, Fax: +86-551-63601592; E-mail: chenjiej@mail.ustc.edu.cn;

Prof. Han-Qing Yu, Fax: 86-551-63607592, E-mail: hqyu@ustc.edu.cn. 


\section{Abstract}

Since nitrate causes severe ecological and health risks, nitrate contamination of drinking water sources has become one of the most important water quality concerns all over the world. Photocatalytic reduction of nitrate to molecular nitrogen presents a promising approach to remove nitrate from drinking water sources. However, harmful intermediates like $\mathrm{NO}_{2}{ }^{-}, \mathrm{NO}, \mathrm{NO}_{2}$ and $\mathrm{N}_{2} \mathrm{O}$ are usually formed, and metal loading or hole scavengers are generally needed to reduce the recombination of photo-generated electrons and holes, which will cause secondary pollution to drinking water. In this work, an efficient, selective and sustainable bioelectro-photocatalytic nitrate-reducing system by utilizing commercial $\mathrm{TiO}_{2}$ nanoparticles $\mathrm{P} 25$ as the photocatalyst and bio-electrons from microbial metabolism as the hole scavenger is reported. In this system, bio-electrons extracted from organic substrates in bioanode are transferred to the photocathode through an external circuit for hole quenching. With the utilization of the residual photogenerated electrons, nitrate is completely reduced to nitrogen without accumulation of harmful nitrite or ammonium. The experimental results and the mechanistic analysis using the first-principles density functional theory calculations demonstrate that toxic by-products like nitrite or ammonium will not be accumulated in this system. Thus, this approach has a great potential for sustainable remediation of nitrate-contaminated drinking water sources.

Keywords: Bio-electrons; Denitrifcation; Photocatalysis; Remediation; Titanium dioxide 


\section{Introduction}

Nitrate $\left(\mathrm{NO}_{3}{ }^{-}\right)$is one of the most widespread contaminants in surface water and subsurface aqueous environments, resulting from wide fertilizer use, sewage/livestock wastewater discharge, and landfill leachates, etc (Jensen et al., 2014; Liu et al., 2007; Senn and Hemond, 2002). Nitrate accumulation in water bodies leads to a series of ecological and health problems. For example, algae bloom frequently occurs in freshwaters or estuarines at high nitrate concentrations (Galloway et al., 2008; Lewis et al., 2011). Especially, high contents of nitrate and its reduction intermediates, e.g., nitrite $\left(\mathrm{NO}_{2}^{-}\right)$, in drinking water sources have been demonstrated to cause methemoglobinemia and cancer (Addiscott and Benjamin, 2004; Lundberg et al., 2004). Thus, the World Health Organization has recommended the concentration limit of $50 \mathrm{mg} / \mathrm{l} \mathrm{NO}{ }_{3}^{-}$and $3 \mathrm{mg} / \mathrm{NO}_{2}{ }^{-}$in drinking water. However, their actual nitrate concentrations in drinking water sources, especially in many developing countries like China, mostly far exceed this limit. In the north China plain region where groundwater is a main drinking water source, the groundwater $\mathrm{NO}_{3}{ }^{-}$content reaches up to $160 \mathrm{mg} / \mathrm{l}$, severely threatening drinking water security. Thus, remediation technologies for efficient nitrate elimination without accumulation of harmful intermediates are greatly needed (Foley et al., 2010; Wunderlin et al., 2012).

Currently, physicochemical methods such as ion exchange, reverse osmosis, and electrodialysis have been used to remove nitrate from water, but they generally require further treatment of the concentrated solution, cause the losses of other 
useful elements (Chaplin et al., 2012; Li et al., 2016; Zhang et al., 2014), and usually consume high energy. Biological approaches are useful for nitrate removal from wastewater, though their application for water environmental remediation is limited, due to the challenges of performance maintenance and secondary pollution associated with carbon source supply and the pathogen concerns (Cardoso et al., 2016; Cheng et al., 2012; Pereira et al., 2014). Performance of a biological treatment system is affected by many factors, especially microbial communities involved in the system. The complexity and variations of microbial communities cause the instability and difficulty in performance maintenance of biological treatment systems (Barwal et al., 2014). In addition, such bioconversion is usually incomplete, resulting in the formation of even more harmful by-products such as $\mathrm{NO}_{2}^{-}, \mathrm{NO}, \mathrm{NO}_{2}$ and $\mathrm{N}_{2} \mathrm{O}$ (Peng et al., 2016; Upadhyaya et al., 2012).

In comparison, photocatalytic method presents a more environmentally-benign option, which enables efficient reduction of nitrate to $\mathrm{N}_{2}$ without introducing any chemicals or bacteria and requiring any post-treatment (Choe et al., 2013; Hoffmann et al., 1995; Sa et al., 2009; Zhang et al., 2005). In particular, titanium dioxide $\left(\mathrm{TiO}_{2}\right)$, attributed to its excellent optical and electronic properties, chemical stability, nontoxicity, and low cost, has been extensively investigated for such purposes (Hoffmann et al., 1995). However, $\mathrm{TiO}_{2}$ has a relative poor photocatalytic reduction activity because of the rapid recombination of the photogenerated electrons and holes. Nano-structured $\mathrm{TiO}_{2}$ can even catalyze nitrate production from nitrogen and oxygen (Yuan et al., 2013). To reduce the recombination of electron-hole pairs, metal doping 
or hole scavengers are usually applied. However, this incurs extra costs and arouses environmental concerns on the dosed chemicals (Chaudhuri and Lovley, 2003). In addition, due to a low reaction selectivity, harmful by-products such as nitrite or ammonium are usually generated (Chaudhuri and Lovley, 2003; Cheng et al., 2012). These limitations highlight the needs for more selective, cost-effective and sustainable photocatalytic processes to reduce nitrate to $\mathrm{N}_{2}$ completely.

In this work, we report a novel bioelectro-photocatalytic denitrification system by utilizing commercial $\mathrm{TiO}_{2}$ nanoparticles $\mathrm{P} 25$ as a nitrate-reducing photocatalyst and using bio-electrons derived from microbial metabolism as a cost-effective and sustainable hole scavenger (Chaudhuri and Lovley, 2003; Rabaey and Rozendal, 2010). The geometry structures of the reactants, intermediates, and products adsorbed on the abundant (101) surface of $\mathrm{TiO}_{2}$ nanoparticles in the reaction process in water solution were energy-minimized, and the mechanisms of the highly-selective nitrate reduction were elucidated. This bioelectro-photocatalytic system synergically utilizes both bioenergy and photoenergy for efficient and complete nitrate reduction, and has a potential for nitrate removal from drinking water sources and water environmental remediation.

\section{Materials and methods}

\subsection{Reactor construction and operation}


The system contained a carbon paper bioanode $(3 \times 7 \mathrm{~cm}$, GEFC Co., China) and a $\mathrm{TiO}_{2}$ photocathode, separated by an ion-exchange membrane and electrically connected through a $10 \Omega$ external resistance. The bioanode was pre-cultivated in a microbial fuel cell for 2 months with anaerobic sludge as inoculums and acetate as substrate, thus a consortium of electrochemically active microorganisms was well enriched in the anode chamber. The photocathode was prepared by painting $\mathrm{TiO}_{2}$ (P25, Degussa Co., Germany) on a carbon paper with $0.1 \mathrm{~g}$ of $\mathrm{TiO}_{2}$ loaded (Yuan et al., 2013). The anode chamber was filled with $80 \mathrm{~mL}$ of autoclaved medium containing (in $1 \mathrm{~L}$ of phosphate buffer, $\mathrm{pH} 7.0$ ): $\mathrm{NaAc}, 100 \mathrm{mg} ; \mathrm{NH}_{4} \mathrm{Cl}, 310 \mathrm{mg} ; \mathrm{KCl}$, $130 \mathrm{mg} ; \mathrm{CaCl}_{2}, 10 \mathrm{mg} ; \mathrm{MgCl}_{2} \cdot 6 \mathrm{H}_{2} \mathrm{O}, 20 \mathrm{mg} ; \mathrm{NaCl}, 2 \mathrm{mg} ; \mathrm{FeCl}_{2}, 5 \mathrm{mg}$; $\mathrm{CoCl}_{2} \cdot 2 \mathrm{H}_{2} \mathrm{O}, 1 \mathrm{mg} ; \mathrm{MnCl}_{2} \cdot 4 \mathrm{H}_{2} \mathrm{O}, 1 \mathrm{mg} ; \mathrm{AlCl}_{3}, 0.5 \mathrm{mg} ;\left(\mathrm{NH}_{4}\right)_{6} \mathrm{Mo}_{7} \mathrm{O}_{24}, 3 \mathrm{mg}$; $\mathrm{H}_{3} \mathrm{BO}_{3}, 1 \mathrm{mg} ; \mathrm{NiCl}_{2} \cdot 6 \mathrm{H}_{2} \mathrm{O}, 0.1 \mathrm{mg} ; \mathrm{CuSO}_{4} \cdot 5 \mathrm{H}_{2} \mathrm{O}, 1 \mathrm{mg} ; \mathrm{ZnCl}_{2}, 1 \mathrm{mg}$ (Sun et al., 2008), whereas the cathode chamber was equipped with a quartz glass window $(2 \times 4$ $\mathrm{cm})$ and filled with $0.25 \mathrm{mM}$ nitrate solution $(80 \mathrm{~mL})$. Nitrite and ammonia nitrogen were not added in the initial media.

A 30-W low-pressure mercury lamp was used as the light source. The lamp was fixed outside the cathode chamber, which had a distance of $5 \mathrm{~cm}$ from the photoelectrode surface. $\mathrm{Na}_{2} \mathrm{SO}_{4}$ solution $(0.01 \mathrm{M})$ was used as the catholyte and constantly stirred by a magnetic stirrer at a speed of $200 \mathrm{rpm}$. In all the tests, a mixed catholyte of $0.25 \mathrm{mM}$ nitrate solution and $0.01 \mathrm{M} \mathrm{Na}_{2} \mathrm{SO}_{4}$ was used. All batch tests were carried out in duplicate at ambient temperatures of around $20{ }^{\circ} \mathrm{C}$.

The current was continuously recorded directly with a potentiostat (CHI660C, 
111 Chenhua Inc., China) connected to a computer. The current density was calculated 112 relative to the projected surface area of the bioanode from the current data. The 113 photo-electrochemical response of the system was also analyzed using the potentiostat. 114 The morphology of the prepared $\mathrm{TiO}_{2}$-loaded photoelectrodes was imaged using scanning electron microscopy (SEM) (FEI Co., the Netherlands), and its crystal structure was characterized by X-ray diffraction (XRD, X' Pert PRO, Philips Co., the

117 Netherlands). Both nitrate and nitrite concentrations were analyzed using ion 118 chromatography (ICS-1000, Dionex Co., USA) with a conductometric detector set at $43 \mathrm{~mA}$. A solution containing $8 \mathrm{mM} \mathrm{Na}_{2} \mathrm{CO}_{3}$ and $1 \mathrm{mM} \mathrm{NaHCO}_{3}$ was used as eluent. Ammonia concentration after the Nessler reaction was determined by spectrophotometry (UV-2401, Shimaze Co., Japan) at a wavelength of $420 \mathrm{~nm}$. Co., USA) equipped with an electron-capture detector, and an FTIR (TENSOR 27, Bruker Co., Germany) equipped with a mercury-cadmium-teluride detector for analysis of the potential $\mathrm{NO}_{\mathrm{x}}$ intermediates (Yuan et al., 2013). All reagents used were using deionized water (Millipore Co., USA). 2001). The mechanisms of intermediates formation on the (101) surface of $\mathrm{TiO}_{2} \mathrm{P} 25$ were explored by the first-principles DFT calculations.

$\mathrm{TiO}_{2} \mathrm{P} 25$ contains anatase and rutile phases in a ratio of about 3: 1 (Ohno et al.,

\subsection{Quantum chemical calculations}



oxide, the vacuum region is the space between slabs and has a width of about $10 \AA$. In this model, the vacuum region was usually used to represent the (101) surface of $\mathrm{TiO}_{2}$. Each slab contains $18 \mathrm{Ti}$ atoms and $36 \mathrm{O}$ atoms. The (101) surface consists of $\mathrm{Ti}$ atoms with 5- or 6-fold coordination (Ti-5c, Ti-6c) and $\mathrm{O}$ atoms with 2- or 3-fold coordination (O-2c, O-3c) (He et al., 2009). Nitrate, hydrated proton, water and product molecules were adsorbed on one side of the slab only (Gong et al., 2006; He et al., 2009).

First-principles DFT calculations were performed with the generalized gradient 
to describe the core electrons.

\section{Results and discussion}

\subsection{Catalytic denitrification performance}

The XRD spectrum of the photoelectrode in our work (Fig. 1a) was similar to that of the commercial $\mathrm{TiO}_{2}$ nanoparticles P25 (Yuan et al., 2013). The $\mathrm{TiO}_{2}$-coated electrode displayed cracked-mud structure (Fig. 1a). Clearly, the $\mathrm{TiO}_{2}$ coating increased the electrode surface area without changing the electrode structure.

The current response vs time curves of the denitrification system with or without UV irradiation are shown in Fig. 1b. A higher current, with an average increase of $1.6 \pm 0.3 \mathrm{~mA} / \mathrm{m}^{3}$, was achieved under UV irradiation compared to the non-irradiated control. The change of electric current in response to irradiation occurred rapidly and repeatedly in multiple cycles, suggesting a stable and sensitive light response of the system.

Fig. 2a illustrates the changes of nitrate, nitrite, and ammonium concentrations in the bioelectro-photocatalytic denitrification system. The nitrate concentration decreased by about $60 \%$ within $24 \mathrm{~h}$ and the decreasing rate slowed down, confirming a high denitrification efficiency of this system. By contrast, neither nitrite nor ammonium concentration exhibited a significant increase, indicating a high selectivity of this system towards nitrate reduction to $\mathrm{N}_{2}$ without other harmful by-products. In addition, a comparison between the denitrification efficiencies in the 
177 electrochemical, photocatalytic and bioelectro-photocatalytic systems (Fig. 2b) 178 reveals much better performance of the bioelectro-photocatalytic system. This system 179 had a significantly higher denitrification rate constant $\left(0.0308 \pm 0.0053 \mathrm{~h}^{-1}\right)$ than the 180 individual photocatalytic $\left(0.0011 \pm 0.0015 \mathrm{~h}^{-1}\right)$ and electrochemical $\left(0.0072 \pm 0.0004 \mathrm{~h}^{-1}\right)$ 181 systems (Fig. 2b), indicating that the bio-electrons could be effectively utilized to 182 scavenge the photogenerated holes and improve the photocatalytic denitrification 183 efficiency. Intermediates concentrations in the pure photocatalytic system are shown 184 in SI (Fig. S3). The accumulation of nitrite and ammonia was also observed.

\subsection{Catalytic reduction mechanisms}

The photocatalytic denitrification reaction can be described as below: .

$$
10 \mathrm{e}_{\mathrm{cb}}{ }^{-}+2 \mathrm{NO}_{3}{ }^{-}+12 \mathrm{H}^{+} \rightarrow \mathrm{N}_{2}+6 \mathrm{H}_{2} \mathrm{O}
$$

No nitrite was generated in the bioelectro-photocatalytic denitrification system, indicating a different reaction pathway compared with the conventional denitrification reactions (Supporting Information (SI), Fig. S1). The energy-minimized geometry structures of the reaction intermediates in the bioelectro-photocatalytic system are illustrated in Fig. 3. A combination of linear synchronous transit (LST) and quadratic synchronous transit (QST) methods were used to find the transition state (TS) and structures. The thermodynamic and kinetic characteristics of elementary steps are states is given in Fig. 4. 
(Gong et al., 2006; Gong et al., 2008). The initial step of this photocatalytic process is the adsorption of nitrate intermediate $\left(\left(\mathrm{NO}_{3}{ }^{-}\right)_{\mathrm{ad}}\right)$ onto the $\mathrm{Ti}$ atom of $\mathrm{TiO}_{2}$ (101)

201

202

203

surface, because 4 orbitals in $3 d$ of $\mathrm{Ti}$ (the electronic arrangement is $[\mathrm{Ar}] 3 d^{2} 4 s^{2}$ ) are empty and could accept the lone pair electrons of $\mathrm{O}$ atom in $\mathrm{NO}_{3}{ }^{-}$to form Ti-O bond (Fig. 3b). The $\mathrm{O}_{\mathrm{ad}}$ atom of $\left(\mathrm{NO}_{3}{ }^{-}\right)_{\text {ad }}$ connected on the surface is located on the site of lattice $\mathrm{O}$ in the above layer of $\mathrm{TiO}_{2}(101)$ surface (SI, Fig. S2). The negative Gibbs free energy change $\left(\Delta_{\mathrm{r}} G_{\mathrm{m}}{ }^{\ominus}=-6.908 \mathrm{kcal} / \mathrm{mol}\right)$ indicates that the adsorption of $\mathrm{NO}_{3}{ }^{-}$is thermodynamically favored for he phototcatalytic pathway. Then, the protons from 4 hydronium cations are added on the other $\mathrm{O}$ atoms of $\left(\mathrm{NO}_{3}{ }^{-}\right)_{\mathrm{ad}}$ to form $\mathrm{OH}$ groups (Fig. 4c), which corresponds to the process from State 2 to State 3 (SI, Fig. S1) with a low energy barrier $\left(E_{\mathrm{a}}=1.658 \mathrm{eV}\right)$.

The hydronium cation is a positively charged polyatomic ion with the chemical formula of $\mathrm{H}_{3} \mathrm{O}^{+}$, a type of oxonium ion. This cation is often used to represent the nature of the proton in aqueous solution, which is highly solvated (bound to a solvent). Following the Step II, the intramolecular dehydration reaction between two the vicinal hydroxyl groups in State 3 occurs, resulting in State 4 (Fig. 3d). After that, the protons of $4 \mathrm{H}_{3} \mathrm{O}^{+}$cations bind with the $\mathrm{O}_{1}$ and $\mathrm{O}_{2}$ atoms of the adsorbed intermediates to form the structure with double bond between two $\mathrm{N}$ atoms $(\mathrm{N}=\mathrm{N})$ and $6 \mathrm{H}_{2} \mathrm{O}$ molecules (Fig. 3e). This process (from State 4 to State 5) has a more negative $\Delta_{\mathrm{r}} G_{\mathrm{m}}{ }^{\ominus}$ value, indicating that the protons attached on the $\mathrm{O}_{1}$ and $\mathrm{O}_{2}$ atoms with a high reactivity is energetically favorable and the bond cleavage of $\mathrm{N}-\mathrm{O}_{1}$ and $\mathrm{N}-\mathrm{O}_{2}$ occurs 

surface of $\mathrm{TiO}_{2}$ (Fig. 3f), and the proton-coupled photogenerated electrons interact

222 with the reactive $\mathrm{O}_{a d}$ to generate other two $\mathrm{H}_{2} \mathrm{O}$ molecules to complete the 223 photocatalytic denitrification reactions.

In the photocatalytic process, the negative $\Delta_{\mathrm{r}} G_{\mathrm{m}}{ }^{\mathrm{e}}$ value of the overall reaction (Table 1) indicates that nitrate reduction on the $\mathrm{TiO}_{2}$ (101) surface is thermodynamically favored at $1 \mathrm{~atm}$ and $298.15 \mathrm{~K}$. The influence of temperature on $\Delta_{\mathrm{r}} G_{\mathrm{m}}$ of the overall photocatalytic denitrification pathway is also investigated. The $\Delta_{\mathrm{r}} G_{\mathrm{m}}$ of the overall reaction becomes more negative at higher temperatures (SI, Fig. S5), suggesting an elevated photocatalytic denitrification rate with the increasing temperature. bio-electrons from the bioanode are efficiently utilized to restrain the recombination system are shown in Fig. 4.The total energy of the system changes with the evolution of the electrons and holes at the photocathode, resulting in a complete and selective denitrification. Expectedly, electrons generated from other origins, such as other fuel cell, photovoltaic cells or wind turbines, can also be used to drive this photocatalytic process. Thus, it provides a common way to increase the efficiency and selectively of photocatalytic denitrification by coupling electron generation device with photocatalytic denitrification process.

The $E_{\mathrm{a}}$ of each step and the transition state structures of Steps IV and VI in our of intermediate structures in the multi-catalytic process. Step I is the adsorption 
process for $\mathrm{NO}_{3}^{-}$located on the surface. Moreover, the high $E_{\mathrm{a}}$ value of the rate-controlling step $\mathrm{V}(3.115 \mathrm{eV})$ indicates that the $\mathrm{N}-\mathrm{O}$ bond cleavage in the structure shown in Fig. 3e should overcome a relatively high barrier to form the third valence bond between two $\mathrm{N}$ atoms. Elementary reactions with a negative $E_{\mathrm{a}}$ are typically barrierless reactions, in which the occurrence of reaction relies on the capture of molecules in a potential well. Thus, the negative $E_{\mathrm{a}}$ values of Steps IV and VI (Table 1) imply that the proton-coupled electron transfer reaction occurs without barrier, rapidly accomplishing the reduction reaction. Compared with the conventional denitrification mechanism shown in SI (Table S1 and Fig. S6), such a bioelectro-photocatalytic reaction pathway has a lower $E_{\mathrm{a}}$ (Fig. 4), suggesting that the complete photocatalytic reduction of nitrate to $\mathrm{N}_{2}$ without accumulation of toxic intermediates is energetically feasible.

The complete photocatalytic reduction of nitrate to $\mathrm{N}_{2}$ in our system should be attributed to the devoid of competitive nitrate absorption on the $\mathrm{TiO}_{2}$ surface. Since the desirable product nitrogen contains two nitrogen atoms and nitrate has one nitrogen atom only, a pair of nitrate species has to meet on the active sites of the photocatalyst surface to form nitrogen. Compared with the dose of hole scavengers such as the most utilized formic acid (Zhang et al., 2005), whose adsorption energy $\left(\Delta E_{\text {ad }}\right)$ value on the $\mathrm{TiO}_{2}(101)$ surface is almost five times larger than that of $\mathrm{NO}_{3}^{-}$

(Fig. 5), in our system less compounds will compete with nitrate for the absorption sites on the photocatalyst surface (Kormann et al., 1991). Thus, the scavenging of holes by the bio-electrons enables more homogeneous absorption and activation of 
nitrate atoms pairs simultaneously for the final formation of $\mathrm{N}_{2}$ from nitrate, resulting in the selective and efficient photocatalytic denitrification.

\section{Conclusions}

The bioelectro-photocatalytic system exhibits a high selectivity for photocatalytic reduction of nitrate to $\mathrm{N}_{2}$. This work demonstrates that bio-electrons from microbial metabolism of organic substrates could be effectively utilized to scavenge photogenerated holes and enhance photocatalytic denitrification. Compared with the conventional photocatalytic denitrification, this bioelectro-photocatalytic system has several advantages: (i) greater denitrification rate; (ii) higher selectivity and no accumulation of harmful by-products like nitrite or ammonium, (iii) no extra supply of hole scavenger, and (iv) cost effectiveness, because only a bioanode and a low-cost, facially-fabricated photocathode are required. In the future, improved design of a bioelectro-photocatalytic system and modification of photocatalyst are expected to further enhance the system performance. In addition, the bioelectricity-driven photoreduction approach demonstrated here might be also applicable to the effective reduction of other oxidative contaminants in water such as oxyanions, nitrosamines or even soluble arsenic, thus providing an efficient and environmentally-benign way for removing a variety of pollutants from water.

\section{Acknowledgements}



and 51538011) and the Collaborative Innovation Center of Suzhou Nano Science and

Technology of the Ministry of Education of China for the support of this work.

\section{Appendix A. Supplementary material}

Supplementary data related to this article can be found online.

292

Addiscott, T.M., Benjamin, N., 2004. Nitrate and human health. Soil Use Manage. 20(2), 98-104.

Barwal, A. and Chaudhary, R. 2014. To study the performance of biocarriers in moving bed biofilm reactor (MBBR) technology and kinetics of biofilm for retrofitting the existing aerobic treatment systems: a review. Reviews in Environmental Science and Bio-Technology 13(3), 285-299.

Cardoso, J.C., Bessegato, G.G., Zanoni, M.V.B., 2016. Efficiency comparison of ozonation, photolysis, photocatalysis and photoelectrocatalysis methods in real textile wastewater decolorization. Water Res. 98, 39-46.

Chaplin, B.P., Reinhard, M., Schneider, W.F., Schueth, C., Shapley, J.R., Strathmann, T.J., Werth, C.J., 2012. Critical review of Pd-based catalytic treatment of priority contaminants in water. Environ. Sci. Technol. 46(7), 3655-3670.

Chaudhuri, S.K., Lovley, D.R., 2003. Electricity generation by direct oxidation of 

1229-1232.

Cheng, K.Y., Ginige, M.P., Kaksonen, A.H., 2012. Ano-cathodophilic biofilm Technol. 46(18), 10372-10378.

Choe, J.K., Mehnert, M.H., Guest, J.S., Strathmann, T.J., Werth, C.J., 2013. catalyzes both anodic carbon oxidation and cathodic denitrification. Environ. Sci. Comparative assessment of the environmental sustainability of existing and emerging perchlorate treatment technologies for drinking water. Environ. Sci. Technol. 47(9), 4644-4652.

Delley, B., 1996. Fast calculation of electrostatics in crystals and large molecules. J. Phys. Chem. 100(15), 6107-6110.

Delley, B., 2000. From molecules to solids with the dmol(3) approach. J. Chem. Phys. 113(18), 7756-7764.

Foley, J., de Haas, D., Yuan, Z.G., Lant, P., 2010. Nitrous oxide generation in full-scale biological nutrient removal wastewater treatment plants. Water Res. 44(3), 831-844.

Galloway, J.N., Townsend, A.R., Erisman, J.W., Bekunda, M., Cai, Z., Freney, J.R., Martinelli, L.A., Seitzinger, S.P., Sutton, M.A., 2008. Transformation of the nitrogen cycle: recent trends, questions, and potential solutions. Science $320(5878), 889-892$.

Gong, X.Q., Selloni, A., Batzill, M., Diebold, U., 2006. Steps on anatase $\mathrm{TiO}_{2}(101)$. Nature Mater. 5(8), 665-670. 
Gong, X.Q., Selloni, A., Dulub, O., Jacobson, P., Diebold, U., 2008. Small Au and Pt clusters at the anatase $\mathrm{TiO}_{2}(101)$ surface: behavior at terraces, steps, and surface oxygen vacancies. J. Am. Chem. Soc. 130(1), 370-381.

He, Y., Tilocca, A., Dulub, O., Selloni, A., Diebold, U., 2009. Local ordering and electronic signatures of submonolayer water on anatase $\mathrm{TiO}_{2}(101)$. Nature Mater, 8(7), 585-589.

Hoffmann, M.R., Martin, S.T., Choi, W.Y., Bahnemann, D.W., 1995. Environmental applications of semiconductor photocatalysis. Chem. Rev. 95(1), 69-96.

Jensen, V.B., Darby, J.L., Seidel, C., Gorman, C., 2014. Nitrate in potable water supplies: alternative management strategies. Crit. Rev. Enviro. Sci. Technol. 44(20), 2203-2286.

Kormann, C., Bahnemann, D.W., Hoffmann, M.R., 1991. Photolysis of chloroform and other organic-molecules in aqueous $\mathrm{TiO}_{2}$ suspensions. Environ. Sci. Technol. 25(3), 494-500.

Lewis, W.M., Jr., Wurtsbaugh, W.A., Paerl, H.W., 2011. Rationale for control of anthropogenic nitrogen and phosphorus to reduce eutrophication of inland waters. Environ. Sci. Technol. 45(24), 10300-10305.

Li, G.Y., Liu, X.L., An, T.C., Wong, P.K., Zhao, H.J., 2016. A novel method developed for estimating mineralization efficiencies and its application in pc and pec degradations of large molecule biological compounds with unknown chemical formula. Water Res. 95, 150-158.

Liu, S., Chang, Y., Guo, Y., Lu, C., 2007. Nitrate in groundwater and unsaturated 
Lundberg, J.O., Weitzberg, E., Cole, J.A., Benjamin, N., 2004. Nitrate, bacteria and human health. Nature Rev. Microbiol. 2(8), 681-681.

Ohno, T., Sarukawa, K., Tokieda, K., Matsumura, M., 2001. Morphology of a $\mathrm{TiO}_{2}$ photocatalyst (Degussa, P-25) consisting of anatase and rutile crystalline phases. J. Catal. 203(1), 82-86.

Peng, L., Liu, Y., Gao, S.H., Chen, X., Ni, B.J., 2016. Evaluating simultaneous chromate and nitrate reduction during microbial denitrification processes. Water Res. 89, 1-8.

Pereira, J., Reis, A.C., Homem, V., Silva, J.A., Alves, A., Borges, M.T., Boaventura, R.A.R., Vilar, V.J.P., Nunes, O.C., 2014. Solar photocatalytic oxidation of recalcitrant natural metabolic by-products of amoxicillin biodegradation. Water Res. 65, 307-320.

Rabaey, K., Rozendal, R.A., 2010. Microbial electrosynthesis-revisiting the electrical route for microbial production. Nature Rev. Microbiol. 8(10), 706-716.

Sa, J., Agueera, C.A., Gross, S., Anderson, J.A., 2009. Photocatalytic nitrate reduction over metal modified $\mathrm{TiO}_{2}$. Appl. Catal. B-Environ. 85(3-4), 192-200.

Segall, M.D., Lindan, P.J.D., Probert, M.J., Pickard, C.J., Hasnip, P.J., Clark, S.J., Payne, M.C., 2002. First-principles simulation: ideas, illustrations and the castep code. J. Phys.-Condens. Mat. 14(11), 2717-2744.

Senn, D.B., Hemond, H.F., 2002. Nitrate controls on iron and arsenic in an urban lake. Science 296(5577), 2373-2376. 
Sun, M., Sheng, G.-P., Zhang, L., Xia, C.-R., Mu, Z.-X., Liu, X.-W., Wang, H.-L., Yu, H.-Q., Qi, R., Yu, T., Yang, M., 2008. An Mec-Mr-coupled system for biohydrogen production from acetate. Environ. Sci. Technol. 42(21), 8095-8100.

Upadhyaya, G., Clancy, T.M., Snyder, K.V., Brown, J., Hayes, K.F., Raskin, L., 2012. Effect of air-assisted backwashing on the performance of an anaerobic fixed-bed bioreactor that simultaneously removes nitrate and arsenic from drinking water sources. Water Res. 46(4), 1309-1317.

Wunderlin, P., Mohn, J., Joss, A., Emmenegger, L., Siegrist, H., 2012. Mechanisms of $\mathrm{N}_{2} \mathrm{O}$ production in biological wastewater treatment under nitrifying and denitrifying conditions. Water Res. 46(4), 1027-1037.

Yuan, S.J., Chen, J.J., Lin, Z.Q., Li, W.W., Sheng, G.P., Yu, H.Q., 2013. Nitrate formation from atmospheric nitrogen and oxygen photocatalysed by nano-sized titanium dioxide. Nature Commun. 4, 2249.

Zhang, A.Y., Long, L.L., Liu, C., Li, W.W., Yu, H.Q. 2014. Electrochemical degradation of refractory pollutants using $\mathrm{TiO}_{2}$ single crystals exposed by high-energy \{001\} facets. Water Res. 66(1), 273-282.

Zhang, A.Y., Wang, W.K., Pei, D.N., Yu, H.Q. 2016. Degradation of refractory pollutants under solar light irradiation by a robust and self-protected $\mathrm{ZnO} / \mathrm{CdS} / \mathrm{TiO}_{2}$ hybrid photocatalyst. Water Res. 92(1), 78-86.

Zhang, F.X., Jin, R.C., Chen, J.X., Shao, C.Z., Gao, W.L., Li, L.D., Guan, N.J., 2005. High photocatalytic activity and selectivity for nitrogen in nitrate reduction on $\mathrm{Ag} / \mathrm{TiO}_{2}$ catalyst with fine silver clusters. J. Catal. 232(2), 424-431. 
Table 1 - Calculated thermodynamic and kinetic properties of the $\mathrm{NO}_{3}{ }^{-}$reduction in the bioelectro-photocatalytic denitrification system by LST/QST. The $\mathrm{NO}_{3}{ }^{-}$reduction on the anatase $\mathrm{TiO}_{2}(101)$ surface at $298.15 \mathrm{~K}$ and $1 \mathrm{~atm}$, and the energy barrier of every step corresponds to the bioelectron-assisted way shown in Fig. 4.

\begin{tabular}{lcccc}
\hline \multicolumn{1}{c}{ Step } & $\Delta_{\mathrm{r}} G_{\mathrm{m}}{ }^{\ominus}$ & $\Delta_{\mathrm{r}} H_{\mathrm{m}}{ }^{\ominus}$ & $\Delta_{\mathrm{r}} S_{\mathrm{m}}{ }^{\ominus}$ & $E_{\mathrm{a}}$ \\
& $(\mathrm{kcal} / \mathrm{mol})$ & $(\mathrm{kcal} / \mathrm{mol})$ & $(\mathrm{cal} / \mathrm{mol} \mathrm{K})$ & $(\mathrm{eV})$ \\
\hline $1+2 \mathrm{NO}_{3}{ }^{-} \rightarrow 2$ & -6.908 & -11.145 & -14.211 & - \\
$2+4 \mathrm{H}^{+}+2 \mathrm{e}_{\mathrm{cb}}{ }^{-} \rightarrow 3$ & -186.016 & -178.117 & 26.494 & 1.658 \\
$3 \rightarrow 4+2 \mathrm{H}_{2} \mathrm{O}$ & -68.227 & -72.432 & -14.105 & 2.265 \\
$4+4 \mathrm{H}^{+}+4 \mathrm{e}_{\mathrm{cb}}{ }^{-} \rightarrow 5+2 \mathrm{H}_{2} \mathrm{O}$ & -269.880 & -254.843 & 50.432 & -2.559 \\
$5 \rightarrow 6+\mathrm{N}_{2}$ & 20.949 & 19.797 & -3.862 & 3.115 \\
$6+4 \mathrm{H}^{+}+4 \mathrm{e}_{\mathrm{cb}}{ }^{-} \rightarrow 1+2 \mathrm{H}_{2} \mathrm{O}$ & -397.768 & -391.597 & 20.697 & -0.199 \\
Total & -907.850 & -888.337 & 65.445 & - \\
\hline
\end{tabular}




\section{Figure captions}

Fig. 1. Characteristics of the photoelectrode. XRD spectrum (a) and SEM images (b) of the $\mathrm{TiO}_{2}$ photoelectrode. A represents anatase and $\mathrm{R}$ represents rutile; and (c) Current vs time of the denitrification reactor under UV irradiation. Equilibrium current without UV irradiation was about $0.05 \mathrm{~mA}$ and peak current reached $0.4 \mathrm{~mA}$ with the UV light on.

Fig. 2. Performance of the bioelectro-photocatalytic denitrification system. (a) the change of nitrate, nitrite, and ammonium concentrations in denitrification process; (b) the relative concentration profiles of nitrate during denitrification process in the bioelectro-photocatalytic system ( $\bullet$ : with bioanode to supply the bio-electrons but without irradiation; $\bigcirc$ : with UV irradiation but without connecting to the bioanode; $\square$ : with both UV irradiation and bio-electrons supply from the bioanode).

Fig. 3. Optimized structures of every step in the photocatalytic denitrification process on the $\mathrm{TiO}_{2}$ (101) surface. (a) Optimized structures of clean $\mathrm{TiO}_{2}$ (101) surface; (b) $\mathrm{NO}_{3}{ }^{-}$adsorbed on the $\mathrm{Ti}$ atom with the $\mathrm{O}_{\mathrm{ad}}$ atom on the site of lattice oxygen position; (c-e) Intermediates of reduction process with the partial top view in the insets; and (f) Nitrogen $\left(\mathrm{N}_{2}\right)$ generation.

Fig. 4. Comparison of energy barrier $\left(E_{\mathrm{a}}\right)$ for photocatalytic denitrification in the bioelectron-assisted way and the conventional pathway. The $E_{\mathrm{a}}$ of each step for $\mathrm{NO}_{3}{ }^{-}$ reduction on the $\mathrm{TiO}_{2}$ (101) surface with the transition state (TS) structures of Steps IV and VI in the bioelectro-photocatalytic system. Step I in the bioelectro-photocatalytic system is the adsorption of $\mathrm{NO}_{3}{ }^{-}$on the $\mathrm{TiO}_{2}(101)$ surface.

Fig. 5. $\mathrm{NO}_{3}^{-}$and formate $\left(\mathrm{HCOO}^{-}\right)$adsorbed on $\mathrm{Ti}$ atom of the anatase $\mathrm{TiO}_{2}(101)$ surface. (a) The calculated adsorption energy $\left(\Delta E_{\mathrm{ad}}=E_{\mathrm{TiO} 2}+E_{\mathrm{NO} 3}-E_{\mathrm{NO} 3-\mathrm{TiO} 2}\right)$ of $\mathrm{NO}_{3}{ }^{-}$on the $\mathrm{TiO}_{2}$ (101) surface is $0.21 \mathrm{eV}$; and (b) the $\Delta E_{\mathrm{ad}}$ of $\mathrm{HCOO}^{-}$is almost five times larger than $\mathrm{NO}_{3}{ }^{-}$ 
a

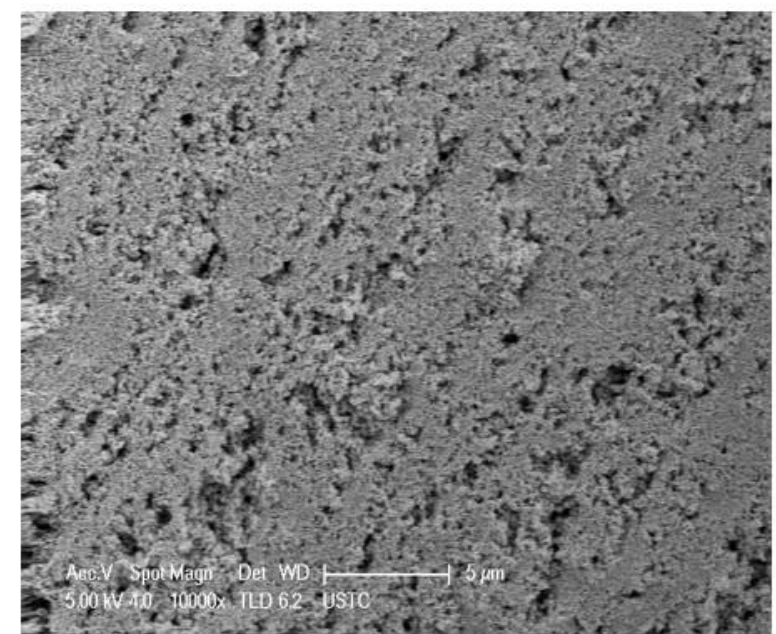

b

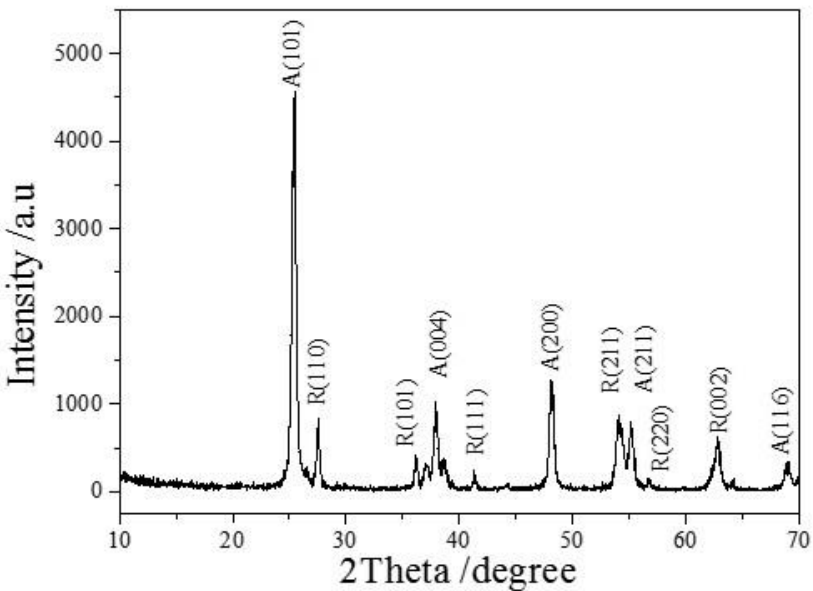

c

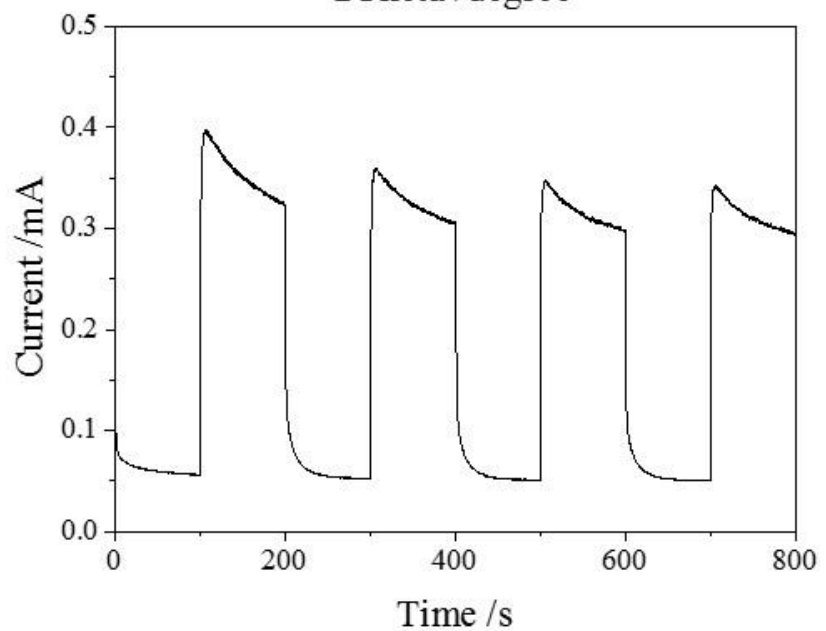

Fig. 1 

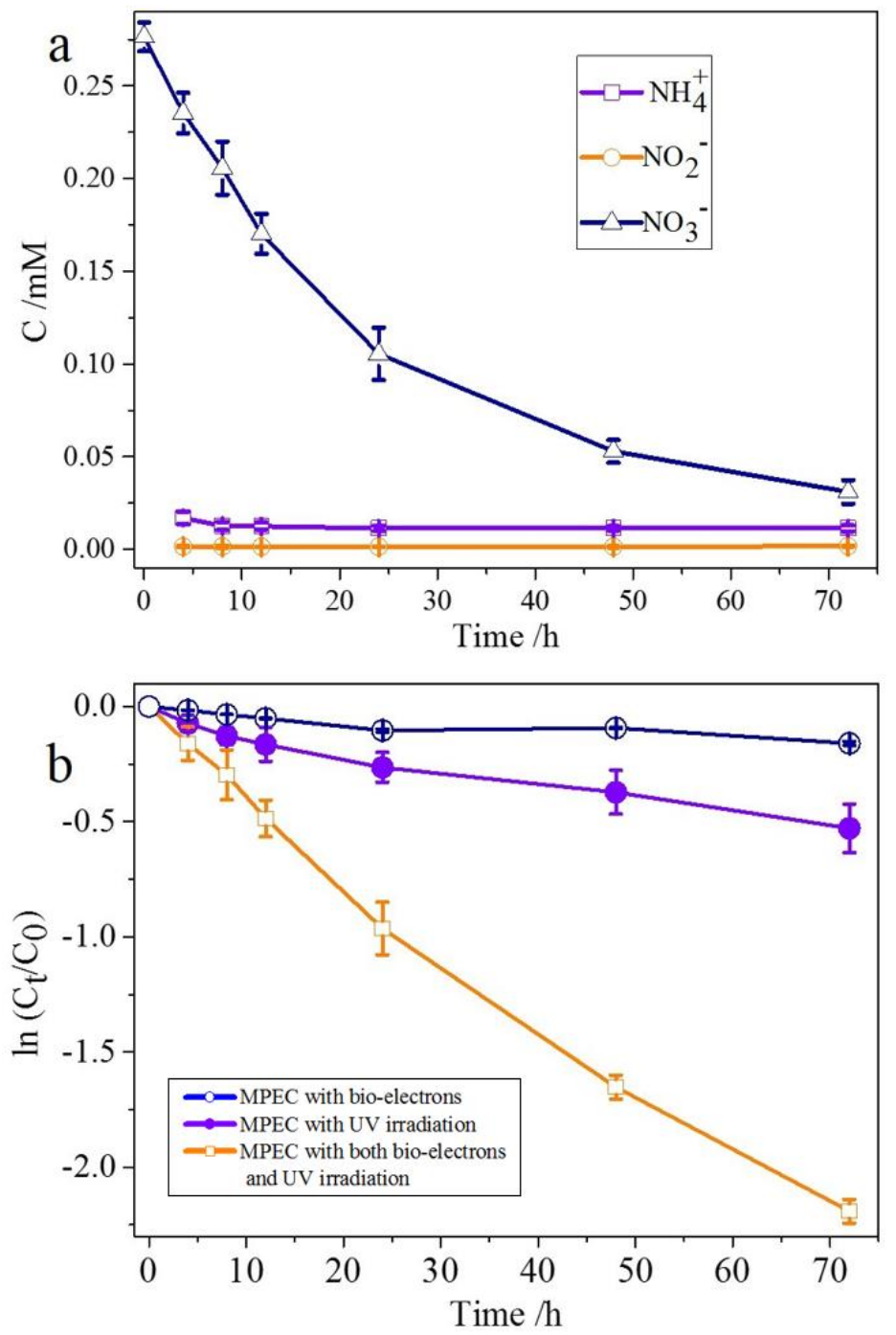

Fig. 2 


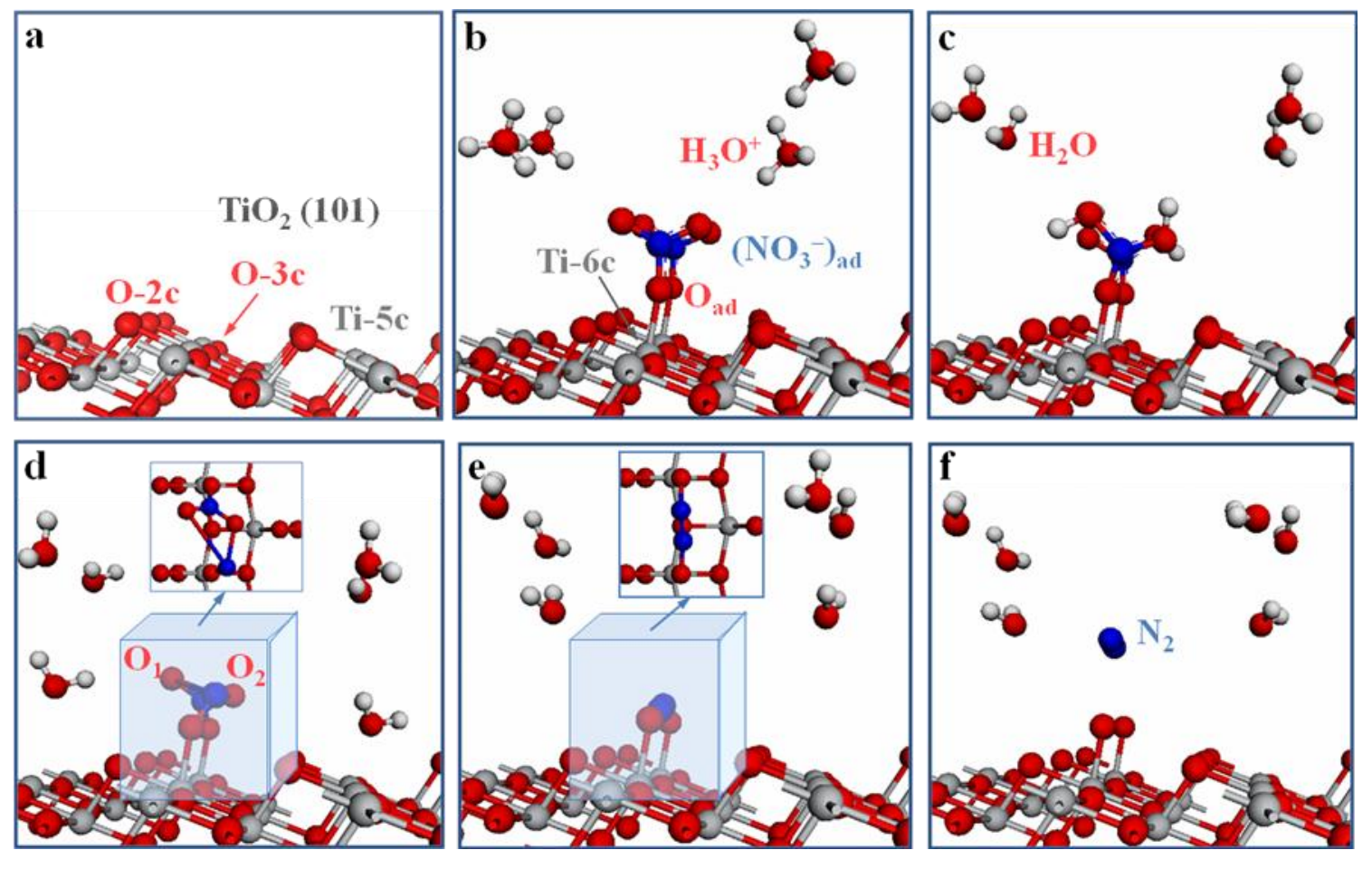

Fig. 3 


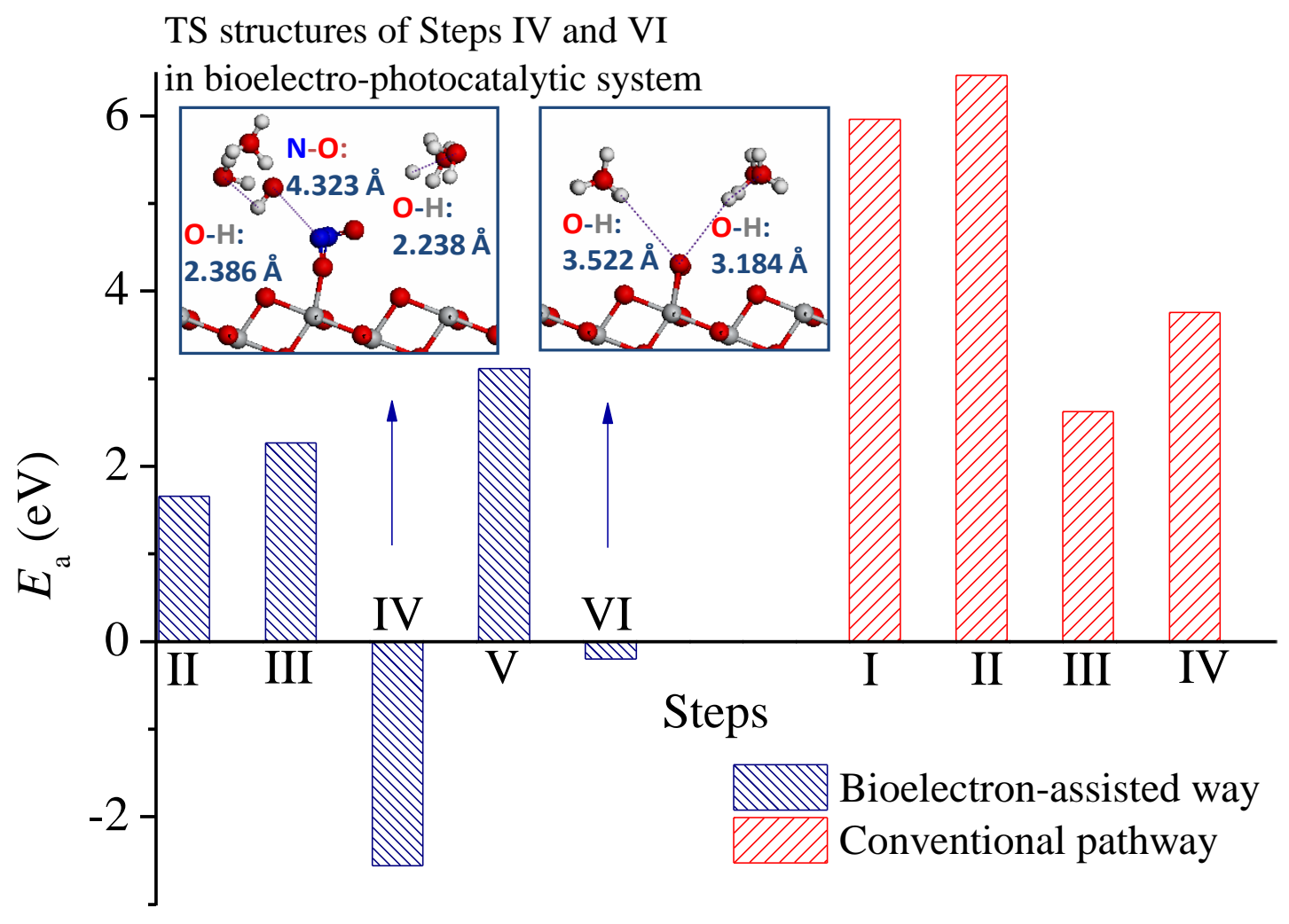

Fig. 4 

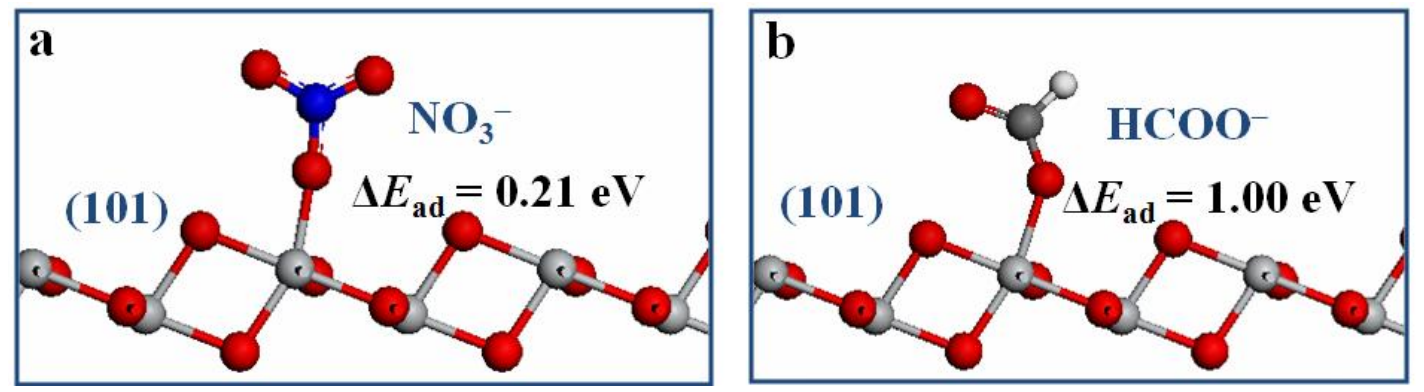

Fig. 5 
Graphical Abstract

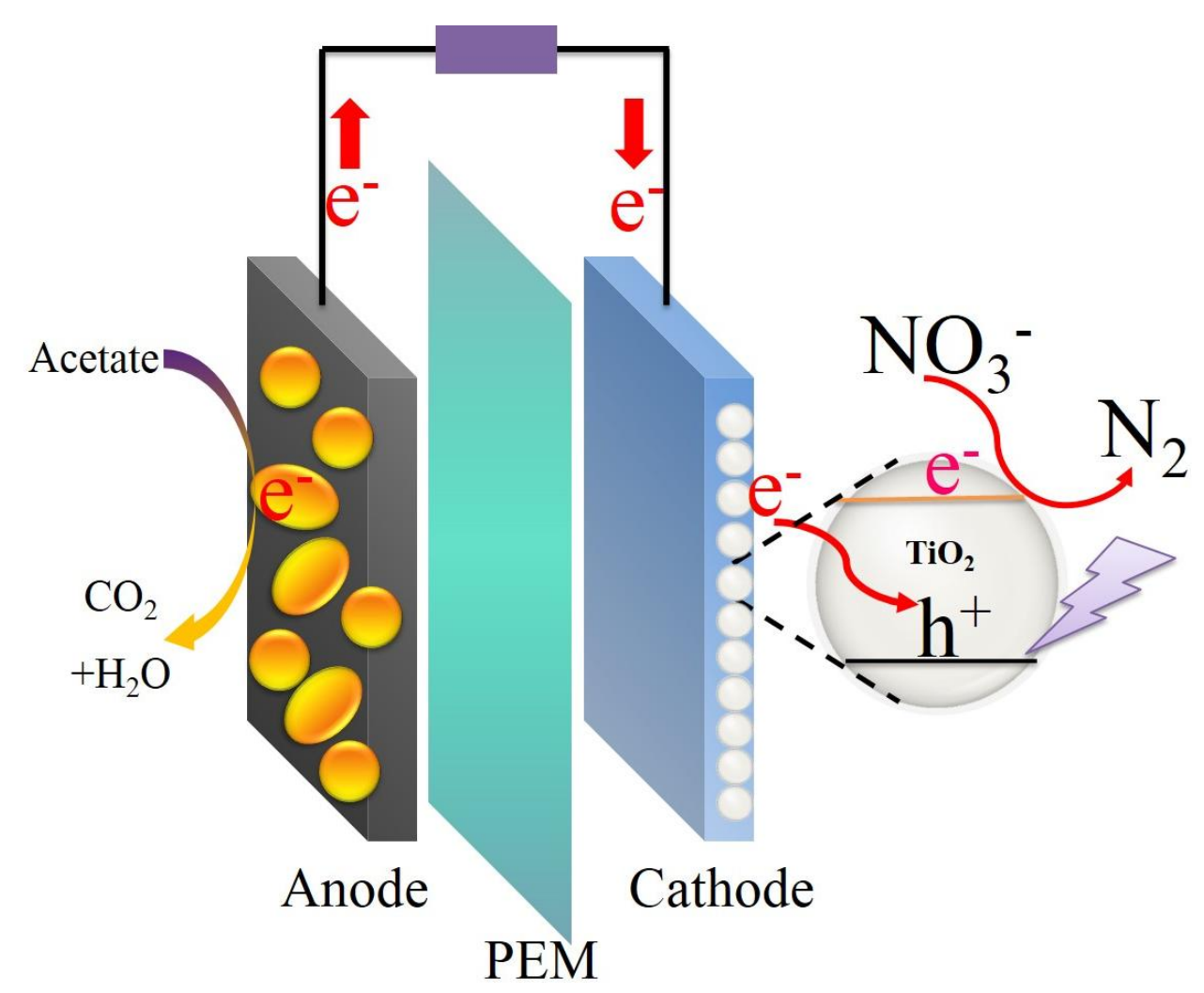

